\title{
Ortaokul Öğrencilerinin Beden Eğitimi ve Spor Dersi Sportmenlik Davranışlarının Bazı Değişkenlere Göre İncelenmesi
}

\author{
DOI: 10.26466/opus.570922 \\ Meryem Altun ${ }^{*}$ - Burcu Güvendi** \\ * Dr. Öğr. Üyesi Niğde Ömer Halisdemir Üniversitesi BESYO, Bor/Niğde/Türkiye \\ E-Posta: mrymltn@hotmail.com ORCID: $\underline{0000-0003-1224-7927}$ \\ ** Arş.Gör. Dr. İstanbul Üniversitesi Spor Bilimleri Fakültesi, Avcılar/İstanbul/Türkiye \\ E-Posta: burcuguvendi@gmail.com ORCID:
}

Öz

Bu çalışmanın amacı ortaokul öğrencilerinin beden eğitimi ve spor dersi sportmenlik davranışlarının bazı değişkenlere göre incelemektir.Bu araştırmada tarama modeli kullanılmıştır. Araştırmanın çalışma grubunu 215'i kız, 236'sı erkek olmak üzere toplamda 451 ortaokul öğrencisi oluşturmaktadır. Veri toplama aracı olarak kişisel bilgi formu ile Beden Eğitimi Dersi Sportmenlik Ölçeği'nden yararlanılmıştır. Araştırmada istatistiksel program olarak SPSS-20 paket programı kullanılmıştır.Verilerin normal dă̆ılım gösterip göstermediğini belirlemek için Kolmogorov-Smirnov testi uygulanmış ve elde edilen $p$ değerleri incelendiğinde ise verilerin nonparametrik dağılıma uygun olduğu görülmüş̧ür.Verilerin analizinde frekans, yüzdelik gibi betimleyici istatistikler ile Mann Whitney U ve Kruskall Wallis analizi kullanılmıştır. Araştırma sonuçlarına göre, öğrencilerin pozitif davranışları sergileme ve negatif davranışlardan kaçınma davranışlarını çok sık sergiledikleri görülmüştür. Genel ortalamaya bakıldığında ise öğrencilerin sportmenlik davranışlarını çok sık sergiledikleri saptanmıştır.Cinsiyete göre kız öğrencilerin sportmenlik toplam puanlarının, erkek öğrencilerin puanlarından anlamlı düzeyde yüksek olduğu belirlenmiştir.Spor yapan öğrencilerin beden eğitiminde pozitif davranışları sergileme puanları, spor yapmayan öğrencilerin puanlarından anlamlı düzeyde yüksektir. 5. sımı öğrencilerin pozitif davranışları sergileme ve sportmenlik toplam puanları 6. 7. ve 8. sinıföğrencilerin puanlarından anlamlı düzeyde yüksek olduğu saptanmıştır. Temaslı spor yapan öğrencilerin pozitif davranışları sergileme puanlarının, temassız spor yapanların ve spor yapmayan öğrencilerin puanlarından anlaml düzeyde yüksek oldŭ̆u saptanmıştır.

Anahtar Kelimeler: $\quad$ Ortaokul öğrencileri, Beden Eğitimi ve Spor, Sportmenlik, Fair play. 


\title{
Investigation of Sportsman Behavior of Secondary School Students in Physical Education and Sports Lesson According to Some Variables
}

\begin{abstract}
The aim of this study is to investigate the sportsmanship behaviors of secondary school students in physical education and sports lessons in terms of some variables. The survey research method was employed in this study. The study group consists of 451 secondary school students, 215 of whom are girls and 236 of whom are boys. The data for this study was collected through "The Personal Data Form" and "Physical Education Course Sport Scale" and it was analyzed with SPSS 20.0 statistical program. First some tests were run to see whether the data was normally distributed or not. When it was found that the distribution was non normal; nonparametric tests were run.Descriptive statistics such as frequency, percentage analysis and Mann Whitney $U$ and Kruskall Wallis tests were used to analyze the data. According to the findings of the study, It was observed that students exhibited positive behaviors and avoidance behaviors very frequently. Based on the general mean, the participants exhibit sportsmanship behaviors very often. In addition, the total score of female students was found to be significantly higher than the scores of male students. The exhibiting positive behaviors in physical education scores of students who do sport were found to be significantly higher than those of students who do not do sports.It was also found that the 5th grade students'exhibiting positive behaviorsand total sportsmanship scores were significantly higher than 6 th, 7 th and 8 th grade students' scores.It was determined that the exhibiting positive behaviors scores of the students who do contact sports were significantly higher than those who do non-contact sports and do not do any sports.
\end{abstract}

Keywords: Secondary school students, Physical education and sports, Sportsmanship, Fair play. 


\section{Giriş}

Beden eğitimi ve spor dersi kendini ifade etme ve yaratıcılık olanakları sağlamaktadır. Serbest zamanların kullanımına katkıda bulunmakta ve estetik beğeniye olanak sağlamaktadır. Beden eğitimi ve spor duyguların kontrol edilmesine katkıda bulunmaktadır. Spor ortamındaki etkileşim duyguların boşalımı ve kontrolü için uygun olanaklar sağlamaktadır. Beden eğitimi ve spor dersi, kişilik gelişimine katkıda bulunmaktadır. Güçlü bağlar, takım ruhu, grup etkileşimi, beden eğitimi ve spor alanlarında görülen özelliklerdir. Takım arkadaşlarına ve rakibe uyum, toplumsal uyumun sağlanmasında etkili olmaktadır (Bucher, 1979). Ahlak, kişinin doğuştan getirdiği ya da deneyimler sonucu kazandığı tutum ve davranışlar toplamı, hak-haksızlık, doğru-yanlış, iyi-kötü gibi konularda bilinçli bir şekilde muhakeme yapma, yapılacaklar ile ilgili kişisel kararı verip bu yönde eylemde bulunmayı kapsayan bilişsel bir yapıdır (Çitemel, 2010). Sporda ahlak anlayışı, iyi ve kötü davranışlar olarak değerlendirilirse; iyi davranışlar fırsat eşitliğini koruma, rakibi düşman olarak görmeme, haksız avantajlardan yararlanmama, işbirliğine ve takım arkadaşlığına yönelik davranabilme, empati kurabilme gibi davranışlarla açılanabilir (Balçıkanlı, 2017).

Sporda centilmenlik ülkemizde daha yaygın olarak sportmenlik kavramı olarak kullanılmaktadır (Tel, Yaman ve Altun, 2017). Sportmenlik kavramı hem sorumlu ve düşünceli bir sporcu olarak rekabetin ve dürüstlügün ifadesi şeklinde yorumlanmakta hem de yüce gönüllülük, sayg1, kibarlık, cana yakınlık, şefkat, cömertlik gibi sözcüklerle açıklanmaktadır (Stornes ve Ommundsen, 2004). Başka bir ifade ile sportmenlik, spor katılımına yönelik olumsuz bir yaklaşımın eksikliği ve spora duyulan sorumlulukla birlikte sporda sosyal normlara, rakibe ve kurallara saygı ve bağlılık şeklinde ifade edilebilir (Balçıkanlı, 2010).

Birçok araştırma ilkokuldan ortaokula geçen öğrencilerde dürüst olmayan davranış sergileme eğiliminin yüksek olduğunu ve bu davranışların önlenmesinde okulların önemli olduğunu belirtmektedir (Seider, Novick ve Gomez, 2013). Fair Play anlayışı, bireyin doğuştan sahip olduğu donanımlarından değildir.Amaca uygun bir eğitim süreci sonucu kazanılabilmektedir (Yıldıran, 2004). 
Beden eğitimi ve spor öğretmenleri, öğrencilerle derslerde benzer kıyafetler içinde olmaları, birlikte oyun oynama ve spor yapma olană̆ına sahip olmaları, antrenman ve müsabakalar nedeniyle okul dışında da birlikte olabilmeleri, seyahat etmeleri, birlikte yemek yemeleri, ortak heyecanlar sonrası üzüntü ve sevinci paylaşabilmeleri nedeniyle öğrenciye daha yakın olabilmekte ve birçok öğrenci için rol model olabilmektedir. $\mathrm{Bu}$ nedenle de değerler eğitimi konusunda isterse en etkin olabilecek öğretmenlerdir (Kunter ve Kunter, 2012). Özellikle ortaokul öğrencilerinin içinde bulunduğu gelişim dönemi olan ergenlik döneminin gelişimsel özelliklerinden kaynaklı bireyde yarattığ ${ }_{1}$ duygusal durumlar, çoğu zaman öğrencilerin hırsına yenik düşmesine neden olabilmektedir. Başkaları tarafından beğenilme, kabul edilme, üstünlük ve başarı ergenlik döneminde görülebilecek özelliklerdendir. Bu özellikler davranışa dönüşerek yeteneklerin sergilenebileceği yerlerden birisi de okullarda verilen beden eğitimi dersleridir. Beden eğitimi derslerinde öğrenciler başarmak adına sportif ahlaki kuralların dışına çıkabilmektedir. Aksine beden eğitimi dersleri öğrencilerin ahlaki değerleri öğrenmesi ve kural bilincinin oluşturulması gereken önemli bir eğitim ortamıdır.

Yıldıran (2004)'a göre okul beden eğitimi dersleri ve okullar arası karşılaşmalar, Fair Play'e uygun davranışların kazandırılmasında uygun bir ortam olarak kullanılmalıdır. Fair Play çalışmalarının, sporcuları mutlak başarı baskısı altında tutan grupların etkisinde kalmadan, etik donanımlara sahip bir genç kuşağın yetiştirilebilmesi ve geleceğin sporcu, antrenör, spor adamı, hakem, yazar ve seyircisinin bu kitle içinden çıkacak olmasından dolayı Fair Play aksiyonlarının yönü ilk ve orta öğretim çağı çocuk ve gençlerine çevrilmelidir.

Her davranışı ile öğrencisine örnek olması gereken diğer branş öğretmenlerin yanında okul dışında müsabakalarda da birlikte olma şanşı bulan beden eğitimi öğretmenlerinin sergiledikleri tutum ve davranış ile verdikleri eğitim öğrencilerin sportif ahlaki değerlere benimsemeleri hususunda önem teşkil etmektedir. Bu bağlamda çalışmamızın amacı ortaokul öğrencilerinde beden eğitimi ve spor dersi sportmenlik davranışlarının bazı değişkenlere göre incelenmesidir. 


\section{Yöntem}

\section{Araştırmanın Modeli}

Araştırmada tarama modeli kullanılmıştır. Tarama modelleri, geçmişte ya da günümüzde mevcut olan bir durumu olduğu biçimde betimlemeyi amaçlayan bir araştırma yaklaşımıdır (Büyüköztürk, 2012).

\section{Araştırmanın Çalışma Grubu}

Araştırmanın çalışma grubunu 215'i kız, 236'sı erkek olmak üzere toplamda 451 ortaokul öğrencisi oluşturmaktadır. Bu öğrencilerin 253'ü spor yaparken 198'i spor yapmamaktadır.

Tablo 1.Katılımcılara Ait Demografik Özellikler

\begin{tabular}{llll}
\hline & & F & \% \\
\hline \multirow{2}{*}{ Cinsiyet } & Kadın & 215 & 47,7 \\
& Erkek & 236 & 52,3 \\
\hline \multirow{4}{*}{ Sınıf } & 5. sinıf & 131 & 29,0 \\
& 6. sinıf & 64 & 14,2 \\
& 7. sinıf & 153 & 33,9 \\
\multirow{2}{*}{ Spor Yapıyor musunuz? } & 8. sinıf & 103 & 22,8 \\
\hline \multirow{3}{*}{ Branş } & Eayır & 198 & 43,9 \\
& Spet & 253 & 56,1 \\
\hline & Temassiz Spor Yapiyorum & 64 & 43,9 \\
& Temasli Spor Yapiyorum & 189 & 14,2 \\
& & & 41,9 \\
\hline
\end{tabular}

\section{Verilerin Toplanması}

Veri toplama aracı olarak kişisel bilgi formu ile Koç (2013) tarafından geliştirilen "Beden Eğitimi Dersi Sportmenlik Ölçeği" kullanılmıştır. Ölçek 5'li likert tipi ölçektir. Orijinal ölçek 11 madde Pozitif Davranışları Sergileme" (PDS) faktörü (madde 1, 2, 4, 7, 9, 11, 12, 14, 16, 19 ve 21 ) ve ters puanlanan 11 madde "Negatif Davranışlardan Kaçınma" (NDK) faktörü (madde 3, 5, 6, 8, 10, 13, 15, 17, 18, 20 ve 22) olmak üzere toplam 22 maddeden oluşmaktadır. Ölçeğin dereceleme biçimi “(5) Her Zaman, (4) Çok Sık, (3) Ara Sıra, (2) Nadiren ve (1) Hiçbir Zaman" şeklinde sıralanmıştır 
(Koç ve Güllü, 2017). NDK Faktörüne ait puanlar ters puanlandı. Ölçeğin toplamından elde edilen puan "Toplam Sportmenlik (TS)" olarak değerlendirilmiştir.

\section{Verilerin Analizi}

Araştırmada istatistiksel program olarak SPSS-20 paket programı kullanılmıştır.Verilerin normal dağılım gösterip göstermediğini belirlemek için Kolmogorov-Smirnov testi uygulanmış ve elde edilen $p$ değerleri incelendiğinde ise verilerin nonparametrik dağılıma uygun olduğu görülmüştür $(p<0.05)$.Verilerin analizinde frekans, yüzdelik gibi betimleyici istatistikler ile Mann Whitney U ve Kruskall Wallis analizi kullanılmıştır.

\section{Bulgular}

Ortaokul öğrencilerinin beden eğitimi ve spor dersi sportmenlik davranışlarının bazı değişkenlere göre incelenmesi amacıyla yapılan bu çalışmanın analiz sonuçları aşağıdaki gibidir;

Tablo 2. Katılımcılara ait Ölçek Ortalama Puanları

\begin{tabular}{llll}
\hline & N & Ort. & Std. Sp. \\
\hline Pozitif Davranışları Sergileme & 451 & 3,67 &, 828 \\
Negatif Davranışlardan Kaçınma & 451 & 4,00 &, 838 \\
Sportmenlik Toplam & 451 & 3,84 &, 677 \\
\hline
\end{tabular}

Tablo 2' de yer alan ölçek ortalama puanlarına göre öğrencilerin pozitif davranışları çok sık sergiledikleri ve ters puanlanan negatif davranışlardan kaçınma davranışını nadiren sergiledikleri görülmüştür. Genel ortalamaya bakıldığında ise öğrencilerin sportmenlik davranışlarına çok sık sergiledikleri saptanmıştır. (Hiçbir zaman: 1,00 - 1,80; Nadiren: 1,81 - 2,60; Ara Sıra: 2,61 - 3,40; Çok Sık: 3,41 - 4,20; Her zaman: 4,21 - 5,0) 
Tablo 3. Cinsiyete Göre Mann Whitney-U Analiz Sonuçları

\begin{tabular}{|c|c|c|c|c|c|}
\hline & Cinsiyet & Sira Değer Ort. & $\mathrm{Z}$ & $\mathbf{U}$ & $\mathrm{p}$ \\
\hline \multirow{2}{*}{$\begin{array}{l}\text { Pozitif Davranışları } \\
\text { Sergileme }\end{array}$} & $\underline{\mathrm{K}} 1 \mathrm{Z}$ & $215 \quad 236,76$ & \multirow{2}{*}{$--1,674$} & \multirow{2}{*}{23057,00} & \multirow{2}{*}{, 094} \\
\hline & Erkek & $236 \quad 216,20$ & & & \\
\hline \multirow{2}{*}{$\begin{array}{l}\text { Negatif } \\
\text { Davranışlardan Kaçınma }\end{array}$} & $\mathrm{K}_{1 \mathrm{Z}}$ & $215 \quad 264,87$ & \multirow{2}{*}{$-6,052$} & \multirow{2}{*}{17012,500} & \multirow{2}{*}{, 000} \\
\hline & Erkek & 236190,59 & & & \\
\hline \multirow{2}{*}{ Sportmenlik Toplam } & $\mathrm{K} 1 \mathrm{Z}$ & $215 \quad 255,96$ & \multirow{2}{*}{$-4,660$} & \multirow{2}{*}{18929,00} & \multirow{2}{*}{,000 } \\
\hline & Erkek & $236 \quad 198,71$ & & & \\
\hline
\end{tabular}

Tablo 3'de cinsiyete göre Beden eğitimi dersi sportmenlik davranışı ölçeğinin pozitif davranışları sergileme alt boyutunda anlamlı farklılık görülmezken ( $p>0.05)$; negatif davranışlardan kaçınma alt boyutunda ve sportmenlik toplam puanlarında anlamlı farklılık görülmüştür $(\mathrm{p}<0.05)$. Analiz sonuçlarına göre; kızların negatif davranışlardan kaçınma puanları $(264,7)$, erkeklerin puanlarından $(190,59)$ anlamlı düzeyde yüksektir. Diğer bir sonuca göre kız öğrencilerin sportmenlik toplam puanlarının $(255,96)$, erkek öğrencilerin puanlarından $(198,71)$ anlamlı düzeyde yüksek olduğu belirlenmiştir.

Tablo 4'de öğrencilerin spor yapma durumuna göre Beden eğitimi dersi sportmenlik davranışı ölçeğinin negatif davranışlardan kaçınma alt boyutunda ve sportmenlik toplam puanlarında anlamlı farklılık görülmezken ( $p>0.05$ ), pozitif davranışları sergileme alt boyutunda anlamlı farklılık görülmüştür $(\mathrm{p}<0.05)$. Analiz sonuçlarına göre; spor yapan öğrencilerin beden eğitiminde pozitif davranışları sergileme puanları $(239,22)$, spor yapmayan öğrencilerin puanlarından $(209,11)$ anlamlı düzeyde yüksektir.

Tablo 4. Spor Yapma Durumuna Göre Mann Whitney-U Analiz Sonuçlarn

\begin{tabular}{|c|c|c|c|c|c|c|}
\hline & $\begin{array}{l}\text { Spor yapiyor } \\
\text { musun? }\end{array}$ & $\mathbf{n}$ & $\begin{array}{l}\text { Sira Değer } \\
\text { Ort. }\end{array}$ & $\mathrm{Z}$ & $\mathrm{U}$ & p \\
\hline \multirow{2}{*}{$\begin{array}{l}\text { Pozitif Davranışları } \\
\text { Sergileme }\end{array}$} & Hayır & 198 & 209,11 & \multirow{2}{*}{\multicolumn{2}{|c|}{$-2,43621703,000$}} & \multirow{2}{*}{,015 } \\
\hline & Evet & 253 & 239,22 & & & \\
\hline \multirow{2}{*}{$\begin{array}{l}\text { Negatif Davranışlardan } \\
\text { Kaçınma }\end{array}$} & Hayır & 198 & 234,14 & \multirow{2}{*}{\multicolumn{2}{|c|}{$-1,17523434,500$}} & \multirow{2}{*}{240} \\
\hline & Evet & 253 & 219,63 & & & \\
\hline \multirow{2}{*}{ Sportmenlik Toplam } & Hayır & 198 & 221,14 & \multirow{2}{*}{,- 701} & \multirow{2}{*}{24084,500} & \multirow{2}{*}{,483 } \\
\hline & Evet & 253 & 229,80 & & & \\
\hline
\end{tabular}


Tablo 5. Sınıf Değişkenine Göre Kruskal Wallis Analiz Sonuçları

\begin{tabular}{|c|c|c|c|c|c|c|}
\hline & SINIF & $\mathrm{n}$ & Sira Değer Ort & $X^{2}$ & $\mathrm{p}$ & U-Testi \\
\hline \multirow{4}{*}{$\begin{array}{l}\text { Pozitif } \\
\text { Davranışları } \\
\text { Sergileme }\end{array}$} & 5. sinif & 131 & 258,88 & & \multirow{4}{*}{,005 } & \multirow{4}{*}{$\begin{array}{l}5>6 \\
5>7 \\
5>8\end{array}$} \\
\hline & $\overline{6 . \sin i f}$ & 64 & 196,64 & & & \\
\hline & 7. sinif & 153 & 217,94 & 13,002 & & \\
\hline & 8. sinif & 103 & 214,40 & & & \\
\hline \multirow{4}{*}{$\begin{array}{l}\text { Negatif } \\
\text { Davranışlardan } \\
\text { Kaçınma }\end{array}$} & 5. sinif & 131 & 247,79 & \multirow{4}{*}{$-6,854$} & \multirow{4}{*}{,077 } & \\
\hline & 6. sinif & 64 & 230,52 & & & \\
\hline & 7. sinif & 153 & 219,81 & & & \\
\hline & 8. sinif & 103 & 204,68 & & & \\
\hline \multirow{4}{*}{$\begin{array}{l}\text { Sportmenlik } \\
\text { Toplam }\end{array}$} & 5. sinif & 131 & 258,39 & \multirow{4}{*}{$-11,695$} & \multirow{4}{*}{,009 } & \multirow{4}{*}{$\begin{array}{l}5>6 \\
5>7 \\
5>8\end{array}$} \\
\hline & 6. sinif & 64 & 211,42 & & & \\
\hline & 7. sinif & 153 & 216,62 & & & \\
\hline & 8. sinif & 103 & 207,81 & & & \\
\hline
\end{tabular}

Tablo 5'de öğrencilerin sınıf değişkenine göre beden eğitimi dersi sportmenlik davranış ölçeğinin negatif davranışlardan kaçınma alt boyutunda anlamlı farklılık görülmezken ( $p>0.05$ ), pozitif davranışları sergileme ve sportmenlik toplam puanlarında anlamlı farklılık görülmüştür $(\mathrm{p}<0.05)$. Analiz sonuçlarına göre 5. sınıf öğrencilerin pozitif davranışları sergileme ve sportmenlik toplam puanları 6.7. ve 8. sinıf öğrencilerin puanlarından anlamlı düzeyde yüksek olduğu saptanmıştır.

Tablo 6. Spor Branşına Göre Kruskal Wallis Analiz Sonuçları

\begin{tabular}{|c|c|c|c|c|c|c|}
\hline & BRANŞ & $\mathbf{n}$ & $\begin{array}{l}\text { Sira } \\
\text { Değer Ort }\end{array}$ & $X^{2}$ & p & U-Testi \\
\hline Pozitif & Spor yapmiyorum & 198 & 209,11 & \multirow{3}{*}{$-9,652$} & \multirow{3}{*}{,008 } & Temasli>spor \\
\hline \multirow{2}{*}{$\begin{array}{l}\text { Davranışları Ser- } \\
\text { gileme }\end{array}$} & -Temassiz spor yapiyorum & 64 & 212,09 & & & yapmayanlar \\
\hline & Temaslı spor yapiyorum & 189 & 248,40 & & & Temaslı $>$ Temassız \\
\hline \multirow{3}{*}{$\begin{array}{l}\text { Negatif } \\
\text { Davranışlardan } \\
\text { Kaçınma } \\
\end{array}$} & Spor yapmiyorum & 198 & 234,14 & \multirow{3}{*}{1,624} & \multirow{3}{*}{,444 } & \\
\hline & Temassiz spor yapiyorum & 64 & 226,56 & & & \\
\hline & Temaslı spor yapiyorum & 189 & 217,28 & & & \\
\hline \multirow{3}{*}{$\begin{array}{l}\text { Sportmenlik } \\
\text { Toplam }\end{array}$} & Spor yapmiyorum & 198 & 221,14 & \multirow{3}{*}{1,038} & \multirow{3}{*}{, 595} & \\
\hline & Temassiz spor yapiyorum & 64 & 219,39 & & & \\
\hline & Temaslı spor yapiyorum & 189 & 233,33 & & & \\
\hline
\end{tabular}

Tablo 6'ya göre öğrencilerin branş değişkenine göre beden eğitimi dersi sportmenlik davranış ölçeğinin negatif davranışlardan kaçınma ve sportmenlik alt boyutunda anlamlı farklılık görülmezken ( $p>0.05)$, pozitif davranışları sergileme alt boyutunda anlamlı farklılık görülmüştür 
$(\mathrm{p}<0.05)$. Analiz sonuçlarına göre temaslı spor yapan öğrencilerin pozitif davranışları sergileme puanlarının $(248,40)$, temassız spor yapanların $(212,09)$ ve spor yapmayan öğrencilerin puanlarından $(209,11)$ anlamlı düzeyde yüksek olduğu saptanmıştır.

\section{Tartışma ve Sonuç}

Bu çalışmada ortaokul öğrencilerinin beden eğitimi ve spor dersi sportmenlik davranışları bazı değişkenlere göre incelenmiştir. Araştırma sonuçlarına göre, öğrencilerin pozitif davranışları ve negatif davranışlardan kaçınma davranışını çok sık sergiledikleri görülmüştür. Genel ortalamaya bakıldığında ise öğrencilerin sportmenlik davranışlarına çok sık sergiledikleri saptanmıştır. O halde çalışmaya katılan öğrencilerin kazanma ya da kaybetme durumu kabullendikleri ve pozitif tutum sergiledikleri söylenebilir.

Cinsiyete göre beden eğitimi ve spor dersi sportmenlik davranışı ölçeğinin pozitif davranışları sergileme alt boyutunda anlamlı farklılık görülmezken ( $p>0.05$ ); negatif davranışlardan kaçınma alt boyutunda ve sportmenlik toplam puanlarında anlamlı farklılık görülmüştür $(\mathrm{p}<0.05)$. Analiz sonuçlarına göre; kızların negatif davranışlardan kaçınma puanları $(264,7)$, erkeklerin puanlarından $(190,59)$ anlamlı düzeyde yüksektir. Diğer bir sonuca göre kız öğrencilerin sportmenlik toplam puanlarının $(255,96)$, erkek öğrencilerin puanlarından $(198,71)$ anlamlı düzeyde yüksek olduğu belirlenmiştir. Kızların toplumsal olarak da hem ailede yetiştirilme tarzları hem de toplumda yüklenen değerlerin etkisi ile daha sakin tutum sergiledikleri söylenebilir. Güvendi, Türkoy-Işım, Özdemir ve Altıncı (2019) tarafından yapılan çalışmada kız öğrencilerin sportmenlik davranışlarını erkek öğrencilerden daha fazla sergiledikleri görülmüştür. Koç ve Güllü (2016)'nün çalışmalarında kızların erkeklere oranla daha sportmen olduğu anlaşılmıştır. Kız öğrencilerde negatif sportmenlik davranışlardan kaçınma düzeyi erkeklere oranla daha iyiyken, pozitif davranışları sergilemede kızlarla erkeklerde çok yakın değerler elde edilmiştir. Araştırma da elde edilen bulgular, alanyazın bulguları ile paralellik göstermektedir. Çalayır vd. (2017), Koç ve Yeniçeri (2017), Esentürk vd. (2015) ile Tsai ve Fung (2005) çalışmalarında bayanların erkeklere göre sportmenlik seviyelerini anlamlı olarak yüksek bulmuştur. Türkmen ve 
Varol (2015)'un çalışmalarında öğrencilerin erkek öğrencilere kıyasla daha yüksek sportmenlik davranış düzeyine sahip oldukları ve yine kız öğrencilerin sportmen olmayan davranışlardan kaçındıkları görülmüştür.Silberman ve Snary (1993) yaptığı çalışmalarında, kızların erkeklerden hem beyin korteksi hem de bilişsel sosyal işlev bakımından iki yıl daha erken olgunlaşmasına bağlı olarak ailenin ahlaki aşaması, sosyal sınıf ve etnik köken açısından sonuçların kızlar lehine olduğunu iddia etmişlerdir.

Öğrencilerin spor yapma durumuna göre beden eğitimi ve spor dersi sportmenlik davranışı ölçeğinin negatif davranışlardan kaçınma alt boyutunda ve sportmenlik toplam puanlarında anlamlı farklılık görülmezken ( $\mathrm{p}>0.05)$, pozitif davranışları sergileme alt boyutunda anlamlı farklılık görülmüştür $(\mathrm{p}<0.05)$. Analiz sonuçlarına göre; spor yapan öğrencilerin beden eğitiminde pozitif davranışları sergileme puanları $(239,22)$, spor yapmayan öğrencilerin puanlarından $(209,11)$ anlaml düzeyde yüksektir. Çalışmaya katılan spor yapan öğrencilerin, sporun bünyesinde barındırdığı ve sporcuya kazandırdığı sportif erdem ve ahlaki değerleri benimsediği ve bu tutumu okul beden eğitimi dersinde de sergilediği söylenebilir.Ortaokul öğrencileriüzerinde yapılan başka bir çalışmada ise sporyapan öğrencilerin yaptıkları spor branşına göreahlak yarg1 düzeyleri anlamlı farklılık göstermemiştir(Akandere vd., 2009). Saygılı vd., (2015)'nın çalışmalarında spor yapan öğrencilerin hem olumlu kişilik özellikleri olarak hem de akademik başarı açısından spor yapmayan öğrencilere göre daha olumlu davranışlara sahip oldukları sonucuna ulaşmışlardır.

Öğrencilerin sınıf değişkenine göre beden eğitimi ve spor dersi sportmenlik davranış ölçeğinin negatif davranışlardan kaçınma alt boyutunda anlamlı farklılık görülmezken ( $\mathrm{p}>0.05$ ), pozitif davranışları sergileme ve sportmenlik toplam puanlarında anlamlı farklılık görülmüştür $(\mathrm{p}<0.05)$. Analiz sonuçlarına göre 5. sınıf öğrencilerin pozitif davranışları sergileme ve sportmenlik toplam puanları 6. 7. ve 8. sınıf öğrencilerin puanlarından anlamlı düzeyde yüksek olduğu saptanmıştır. Milli eğitimin müfredatına göre 4 . sınıfa kadar beden eğitimi dersleri oyun ve fiziki etkinler dersi olarak işlenmektedir. Bu dersler daha çok oyun amaçlı yapılmaktadır. Ancak ikinci bölümde programda değişen ders içerikleri ile beden eğitimi dersi daha teknik ve müsabaların olduğu ders haline almakta ancak 5 . 
sınıftaki öğrencilerin yeni karşılaştıkları programdaki etkinliklere alışmalarının zaman aldığı bu yüzden pozitif davranışları sergilemlerininde daha yüksek olduğu düşünülmektedir. Koç ve Yeniçeri (2017)'nin çalışmalarında sınıf düzeyine göre anlamlı farklılık bulunmuştur. Koç ve Yeniçeri'nin çalışmasında 10. sınıfların pozitif davranışları sergileme, negatif davranışlardan kaçınma ve sportmenlik toplam puanları 9. ve 11. Sinfflardan yüksek olduğu görülmüştür. Türkmen ve Varol (2015)'un çalışmalarında öğrencilerin sınıf düzeylerine bakıldığında, sınıf düzeyi ilerledikçe sportmenlik davranışında düşme görüldüğü ancak belirleyici bir anlamlı farklılık olmadı̆̆ı, gözlemlenmiştir.

Gürpınar (2014) tarafından yapılan çalışmada voleybol oynayan öğrencilerin ahlaki karar alma tutum puanları diğer sporları yapan öğrencilerden yüksek olduğu görülürken futbol oynayan öğrencilerin ahlaki karar alma tutum puanları diğer tüm sporları yapan öğrencilerden düşüktür. Bu sonuçlar spor türlerini başka bir bakış açısıyla değerlendirmeye neden olmuştur. Voleybol temassiz ve futbol da temaslı bir spor olduğundan spor branşları arasındaki bu ilginç fark, spor branşlarını temaslı ve temassız olarak ayırma fikrini ortaya çıkarmıştır. Gürpınar (2014) çalışmasında oyundaki temas oranının artmasının mücadelenin artmasına yol açacağını ve böylelikle galip gelmenin zorlaşacağını ve galibiyet adına haksız avantajlar ve hileler şartlar zorlaştı̆̆ için daha da artabileceğini ifade etmiştir. Bu bakımdan çalışmamızda araştırmaya katılan ve çeşitli branşlarda bireysel ve takım sporu yapan öğrencilerin branşları fiziksel temas içeren ve içermeyen olarak gruplandırılmıştır. Çalışmamızda branş değişkenine göre beden eğitimi ve spor dersi sportmenlik davranış ölçeğinin negatif davranışlardan kaçınma ve sportmenlik alt boyutunda anlamlı farklılık görülmezken ( $p>0.05)$, pozitif davranışları sergileme alt boyutunda anlamlı farklılık görülmüştür $(\mathrm{p}<0.05)$. Analiz sonuçlarına göre temaslı spor yapan öğrencilerin pozitif davranışları sergileme puanlarının $(248,40)$, temassız spor yapanların $(212,09)$ ve spor yapmayan öğrencilerin puanlarından $(209,11)$ anlamlı düzeyde yüksek olduğu saptanmıştır. Koç ve Yeniçeri (2017)'nin çalışmalarında spor türüne göre anlamlı farklılık bulunmuştur. Koç ve Yeniçeri'nin çalışmasına göre fiziksel temas içermeyen sporların pozitif davranışları sergileme, negative davranışlardan kaçınma ve sportmenlik toplam puanlarının topla oynanan takım sporlarına göre yüksek olduğu sonucuna 
ulaşılmıştır. Lee, Whitehead ve Ntoumanis' in (2007) çalışmalarında takım sporu ile uğraşan sporcuların sportmenlik davranışı gösterme eğiliminin, bireysel sporlarla uğraşan sporculardan daha yüksek olduğu sonucuna ulaşmışlardır.

Sonuç olarak öğrencilerin beden eğitimi ve spor dersinde sportif ahlak ve değerlere uygun sportmence davranışlar sergiledikleri söylenebilir. kız öğrencilere göre sportmenlik puanlarının düşük olduğu görülen erkek öğrencilerin daha hırslı ve kazanma odaklı oldukları ve bu yüzden kaybetmeye tahammüllerinin olmadığı düşünülebilir. Bu durumu en aza indirmek amacı ile beden eğitimi derslerinin ilk yarısında far play' e uygun videolar izletilebilir, örnekler verilebilir ve öğrencinin derste sergilemiş olduğu her pozitif davranış ödüllendirilebilir. Pozitif davranış sergileme puanları düşük olan spor yapmayan öğrenciler okul takımlarında ya da kulüplerde spor yapmaya teşvik edilmesi sağlanabilir. 


\title{
EXTENDED ABSTRACT
}

\section{Investigation of Sportsman Behavior of Secondary School Students in Physical Education and Sports Lesson According to Some Variables}

\author{
Meryem Altun - Burcu Güvendi \\ Ömer Halisdemir University, İstanbul University
}

Physical education and sports class provide opportunities for self-expression and creativity. It contributes to the use of free time and enables aesthetic appreciation. Physical education and sports contribute to controlling emotions. The interaction in the sports environment provides proper opportunities for the release and control of emotions. Physical education and sports classes contribute to personality development. Strong ties, team spirit, group interaction are the characteristics seen in physical education and sports. Alignment with teammates and opponents is efficient in ensuring social harmony (Bucher, 1979). Morality is the sum of attitudes and behaviors that a person brings from birth or gains as a result of experiences. It is a cognitive structure that involves making a conscious judgment on issues such as equity-inequity, right-wrong, good-bad, and making personal decisions about what to do and taking actions in this direction (Çitemel, 2010). In sports, if the moral sentiment is considered good and bad behaviors, good behaviors can be explained by behaviors such as maintaining equality of opportunity, not seeing an opponent as an enemy, not taking advantage of unfair advantages, behaving towards cooperation and teammate, empathy (Balçıanlı, 2017).

The survey model was used in the research. Survey models are a research approach that aims to describe a situation that is present in the past or today (Büyüköztürk, 2012). The study group consisted of 451 secondary school students, 215 of whom were girls and 236 of whom were boys. Of these students, 253 do play sports, while 198 do not. As a data collection tool, the "Physical Education Course Sportspersonship Scale" developed by Koç (2013) was used with the personal data form. The scale is a five- 
point Likert type scale. The original scale consists of a total of 22 items, with the 11 items of"Exhibiting Positive Behaviors" (PDS) factor (item 1, $2,4,7,9,11,12,14,16,19$ and 21) and the 11 items which scoring inversely of "Avoidance of Negative Behaviors" (NDK) factor (item 3, 5, 6, 8, 10, 13, $15,17,18,20$ and 22). The grading format of the scale is sorted as "(5) Always, (4) Very often, (3) occasionally, (2) rarely, and (1) Never" (Koç and Güllü, 2017). The scores for the NDK Factor were graded in reverse. The score from the sum of the scale was evaluated as "Total Sportspersonship (TS)." In the research, the SPSS-20 package program was applied as a statistical program. To determine whether the data shows normal distribution, the Kolmogorov-Smirnov Test was implemented, and when the $\mathrm{p}$ values obtained were examined, and the data was found to be suitable for nonparametric distribution $(\mathrm{p}<0.05)$. In the analysis of the data, descriptive statistics such as frequency, percentile, and Mann Whitney $U$ and Kruskal Wallis analysis were used.

According to gender, there were no significant differences in the sub-dimension of Physical Education and Sports Course Sportspersonship Behavior scale in exhibiting positive behaviors $(p>0.05)$, while there were significant differences in the avoidance of negative behaviors sub-dimension and total scores of sportspersonship. According to the results of the analysis, girls' negative behavior avoidance scores are significantly higher than boys' scores. According to another result, it was determined that the total sportspersonship scores of female students were significantly higher than the scores of male students. According to the status of playing the sport of the students, there were no significant differences in the sub-dimension of the physical education and Physical Education and Sports Course Sportspersonship Behavior Scale's avoidance of negative behaviors and total scores of sportspersonship, while there were significant differences in the sub-dimension of exhibiting positive behaviors. According to the results of the analysis, exhibiting positive behaviors in physical education scores of the students who play sports are significantly higher than the scores of the students who do not play sports. In the scores of the students, no significant differences were observed in the sub-dimension of the Physical Education and Sports Course Sportspersonship Behavior Scale's avoidance of negative behaviors according to the class variable. On 
the other hand, significant differences were observed in the scores of exhibiting positive behaviors and total sportspersonship. According to the results of the analysis, the total scores of fifth graders exhibiting positive behaviors and sportspersonship were significantly higher than the scores of sixth, seventh, and eighth graders. In our study, there were no significant differences observed in Physical Education and Sports Course Sportspersonship Behavior Scale's sub-dimensions of the avoidance of negative behaviors and total sportspersonship, according to the branch variable. In the scales' sub-dimension of exhibiting positive behaviors, significant differences were observed. According to the results of the analysis, it was determined that the exhibiting positive behavior scores of the students who play sports interactive were significantly higher than the scores of the students who play sports non-interactive and the students who do not play sports. As a conclusion, it can be stated that the students exhibit sportsperson-like behaviors in physical education and sports course following sporting ethics and values. Male students, who are perceived to have low sportspersonship scores compared to female students, may be considered to be more ambitious and winning-oriented, and therefore do not tolerate losing. To minimize this situation, videos suitable for fair play can be watched in the first half of physical education classes, examples can be given, and every positive behavior exhibited by the student in the course can be rewarded. Students with low exhibiting positive behavior scores and who do not play sports can be encouraged to play sports on school teams or clubs.

\section{Kaynakça / References}

Akandere, M., Baştuğ, G., ve Güler, E. D. (2009). Orta öğretim kurumlarında spora katılımın çocuğun ahlaki gelişimine etkisi. Nĭğde Üniversitesi Beden Ĕ̆itimi ve Spor Bilimleri Dergisi, 3(1), 59-67.

Balçıkanlı, G. S. (2010). Çok boyutlu sportmenlik yönelimi ölçeğinin Türkçe uyarlaması: Geçerlik ve güvenirlik çalışması. Gazi Beden Eğitimi ve Spor Bilimleri Dergisi, 15(1), 1-10

Balçıkanlı, G. S. (2017). Yarışma sporlarının ahlaksal amacı.Spor ve Performans Araştırmaları Dergisi, 8(1), 47-52. 
Bucher, C. A. (1987). Foundations of physical education and sport. Mosby Collage Publishing, Usa.

Büyüköztürk, Ş. (2012).Sosyal bilimler için veri analizi el kitabı. Ankara: Pegem A Yayıncilik.

Çalayır, Ö., Yıldız, N., Yaldız, Ö. vee Çoknaz, H. (2017). Hokey müsabakalarına katılan sporcuların beden eğitimi dersi sportmenlik davranışlarının incelenmesi.İstanbul Üniversitesi Spor Bilimleri Dergisi, 7(2), 27-37.

Çitemel, N. (2010). Lisansüstü öğrencilerinin ahlaki yargı yetenekleri ile psikolojik belirtileri arasındaki ilişkinin incelenmesi. Yüksek Lisans Tezi. Sakarya Üniversitesi Sosyal Bilimler Enstitüsü, Sakarya.

Esentürk, O. K., İlhan, E. L, ve Çelik, O. B. (2015). Examination of high school students' sportsmanlike conducts in physical education lessons according to some variability science. Movement and Health, 15(2), 627-634.

Güvendi, B., Türksoy-Işım, A., Özdemir, H., ve Altıncı, E. E. (2019). Investigation of secondary school students' attitudes toward violence with physical education lessons' sportspersonship behaviours. J Eurasia Sports Sci Med, 1(1), 1-9

Koç, Y. (2013). Sportspersonship behavior scale in physical education course: Validity reliability study. Erzincan University Journal of Education Faculty, 15(1), 96-114.

Koç, Y., ve Güllü, M. (2016). Lise öğrencilerinin beden eğitimi dersi sportmenlik davranışlarının bazı değişkenlere göre incelenmesi. SPORMETRE, 15(1), 19-30.

Koç, Y., ve Yeniçeri, S. (2017). An investigation of the relationship between sportsmanship behavior of students in physical education course and their respect level. Journal of Education and Training Studies, 5(8), 114-122.

Kuter, F. Ö., ve Kuter, M. (2012). Beden eğitimi ve spor yoluyla değerler eğitimi.Eğitim ve İnsani Bilimler Dergisi: Teori ve Uygulama, 3(6), 7594.

Lee, M. J., Whitehead, J., ve Ntoumanis, N. (2007). Development of the attitudes to moral decision-making in youth sport questionnaire (AMDYSQ). Psychology of Sport and Exercise, 8(3), 369-392. 
Saygilı, G., Atay, E., Eraslan, M., ve Hekim, M. (2015). Düzenli olarak spor yapan ve yapmayan öğrencilerin kişilik özellikleri ile akademik başarıları arasındaki ilişkinin incelenmesi.Kastamonu Ĕğitim Dergisi, 23(1), 161-170.

Silberman, M. A., ve Snarey, J. (1993): Gender differences in moral development during early adolescence: The Contribution of sex-related variations in maturation. Current Psychology, 12(2), 163-171.

Stornes, T., ve Ommundsen, Y. (2004). Achievement goals, motivational climate and sportspersonship: A study of yound handball players. Scandinavian Journal of Education, 48(2), 205-221.

Seider, S., Novick, S., ve Gomez, J. (2013). The effects of privileging moral or performance character development in urban adolescents. The Journal of Early Adolescence, 33, 786-821.

Tel, M., Yaman, Ç. ve Altun, M. (2017). Spor bilimleri fakültesi öğrencilerinin sportmenlik davranışları hakkındaki görüşleri. International Journal of Cultural and Social Studies (Intjcss), 3(SI), 16-26.

Tsai, E., ve Fung, L. (2005). Sportspersonship in youth basketball and volleyball players.The Online Journal of Sport Psychology, 7(2).

Türkmen, M, ve Varol, S . (2015). Beden eğitimi ve spor dersinin ortaokul öğrencileri üzerinde sportmenlik davranışı oluşturma etkisinin belirlenmesi: Bartın il örneği. Uluslararası Güncel Eğitim Araştırmaları Dergisi, 1(1), 42-64.

Yıldıran, İ. (2004). Fair Play: Kapsamı,Türkiye'deki görünümü ve geliştirme perspektifleri.Gazi Beden Eğitimi ve Spor Bilimleri Dergisi, 9(4), 3-16.

\section{Kaynakça Bilgisi / Citation Information}

Altun, M. ve Güvendi, B. (2019). Ortaokul öğrencilerinin beden eğitimi ve spor dersi sportmenlik davranışlarının bazı değişkenlere göre incelenmesi. OPUS-Uluslararası Toplum Araştırmaları Dergisi, 11(18), 2224-2240. DOI: 10.26466/opus.570922 